\title{
Long-term survival after perforation of advanced gastric cancer: Case report and review of the literature
}

\author{
Yosuke Adachi, Masanori Aramaki, Norio Shiraishi, Katsuhiro Shimoda, Kazuhiro Yasuda, \\ and Seigo Kitano
}

First Department of Surgery, Oita Medical University, 1-1 Idaigaoka, Hasama-machi, Oita 879-55, Japan

\begin{abstract}
:
Perforation of gastric cancer accounts for less than $1 \%$ of the incidence of acute abdomen, and usually results in a poor outcome. We report a patient who has survived for 6 years and 11 months thus for after emergency total gastrectomy for perforation of advanced gastric cancer. A 49year-old man was admitted with severe abdominal pain. Under the diagnosis of diffuse peritonitis due to peptic ulcer perforation, an emergency total gastrectomy was done. The intraoperative gross diagnosis was Borrmann type 2 tumor with perforation, and extended lymph node dissection and postoperative chemotherapy was therefore added. Histopathologic examination confirmed that the tumor, measuring $7 \times$ $6 \mathrm{~cm}$, was poorly differentiated adenocarcinoma involving the serosa and perigastric lymph nodes. Review of the literature disclosed that long-term survival after perforation of advanced gastric cancer was rare and resulted from curative gastrectomy for stage I tumor without serosal invasion and lymph node metastasis.
\end{abstract}

Key words: gastric cancer, perforation, long-term survival, advanced gastric cancer, gastrectomy, acute abdomen

\section{Introduction}

Perforation of gastric cancer accounts for less than $1 \%$ of the incidence of acute abdomen [1] and few reports of the condition have appeared in the English-language literature in the past 20 years [2,3]. Since perforated gastric cancer is clinically characterized by generalized peritonitis and an advanced stage of the disease, it usually results in a poor outcome, and long-term survival is rare. Factors influencing the surgical results are un-

Offprint requests to: Y. Adachi

Received for publication on Jan. 14, 1998; accepted on Apr. 1, 1998 known, and treatment strategies recommended to surgeons are unclear.

We have experienced a patient who is alive almost 7 years after emergency total gastrectomy for perforation of advanced gastric cancer. To familiarize this condition for gastroenterologists and surgeons, we report the clinicopathologic data for our patient, and we review cases reported in the world literature.

\section{Case report}

A 49-year-old man was admitted to our hospital with severe abdominal pain of sudden onset early in the morning on April 1, 1991. Physical examination showed diffuse abdominal tenderness, muscle guarding, Blumberg's sign, and increased body temperature, of $38.0^{\circ} \mathrm{C}$. Chest roentgenography revealed intraabdominal free air beneath the diaphragm. Under a tentative diagnosis of generalized peritonitis due to peptic ulcer perforation, an emergency operation was performed.

At laparotomy, $600 \mathrm{ml}$ of turbid yellowish ascites was encountered. A small hole was present on the anterior wall of the upper gastric body. With a diagnosis of perforated gastric ulcer, the abdominal cavity was irrigated with $10000 \mathrm{ml}$ of warm saline, and a total gastrectomy was done. However, intraoperative macroscopic diagnosis of the resected stomach disclosed that a Borrmann 2 type tumor, measuring $7 \mathrm{~cm}$ in diameter, was present in the anterior wall of the upper third of the stomach (Figs. 1,2). With a diagnosis of perforated advanced gastric cancer with serosal invasion and lymph node metastasis (S2, N1, H0, P0; stage III) [4], extended lymph node dissection (D2) and splenectomy was performed. Reconstruction was carried out by esophagojejunal anastomosis in a Roux-en-Y fashion, and peritoneal irrigation was done using $10000 \mathrm{ml}$ of warm saline. Operation time was $6 \mathrm{~h} 15 \mathrm{~min}$, and estimated blood loss was $460 \mathrm{~g}$. 


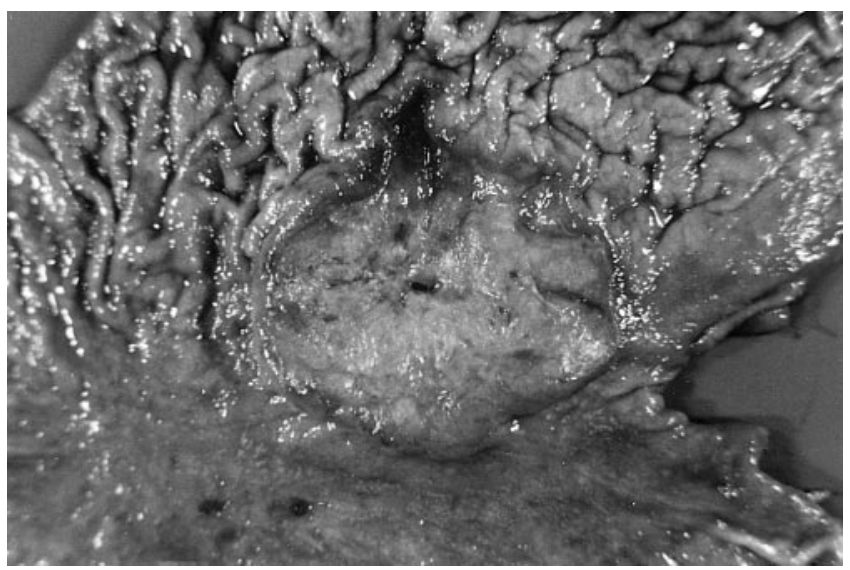

Fig. 1. Mucosal surface of the resected stomach revealed a Borrmann 2 type gastric cancer with perforation at the center of the tumor

The patient recovered uneventfully, and postoperative intravenous chemotherapy was added: etoposide $150 \mathrm{mg}$, three times; doxorubicin $30 \mathrm{mg}$, twice; and cisplatin $60 \mathrm{mg}$, twice over a period of 2 weeks. Histopathologic examination disclosed that the tumor, measuring $8 \times 7 \mathrm{~cm}$, was perforated gastric cancer consisting of poorly differentiated adenocarcinoma invading to the serosa (se, ly1, v1) and involving two perigastric lymph nodes (no.1, n1) [4]. The perforation, measuring $0.5 \mathrm{~cm}$ in diameter, was at the center of the tumor ulceration, which was $7 \times 6 \mathrm{~cm}$ in size. The distance from the tumor margin to the proximal and distal cut ends was 2.0 and $12.0 \mathrm{~cm}$, respectively. The number of dissected lymph nodes confirmed by histologic examination was 40: 25 were perigastric nodes (nos 1-6), 7 were intermediate nodes (nos 7-9), and 8 were distant nodes (nos 10-12) [5]. Pathologically, the disease was stage IIIa, and the operation was curability B [4].

On July 6, 1992, a laparotomy was done for adhesive ileus at the ileum end; locoregional and peritoneal recurrence was not present. Ultrasonography and computed tomography on June 20, 1997 showed no recurrence in the liver, peritoneum, and lymph nodes. The patient is free of disease at the time of writing, December 25, 1997, almost 7 years after the initial operation.

\section{Review of the literature}

Of 140 patients with perforated advanced gastric cancer reported in the Japanese and English literature in the past 10 years, 11 survived for more than 5 years after the operation [6-13]. We summarize their clinicopathologic data (including that of our patient) in Table 1.

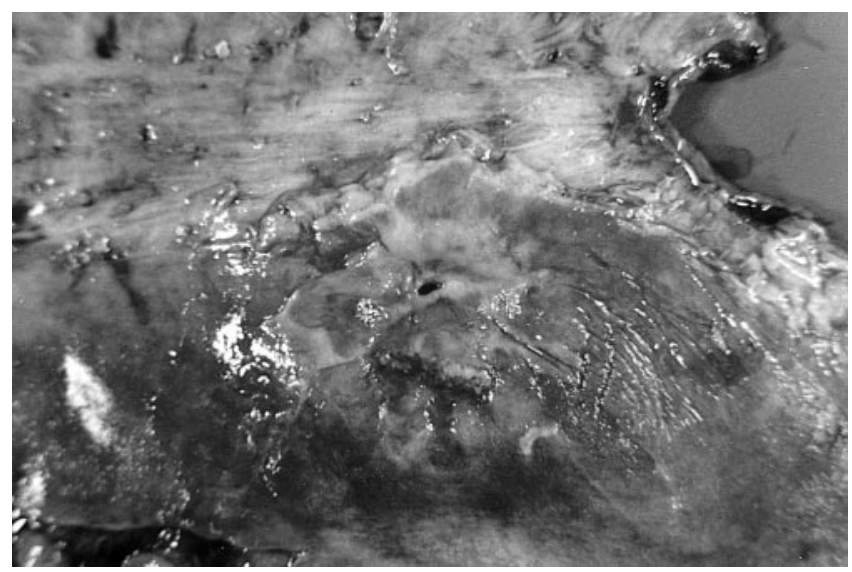

Fig. 2. Serosal surface of the resected stomach demonstrated free perforation with serosal thickening and hardening

The patients ranged in age from 28 to 84 years (mean, 59 years). Eight were men, three were women, and one was unknown. Preoperative diagnosis was perforated gastric cancer in four; in three of these four the perforation was associated with gastric endoscopy. Of the 12 patients, including ours, the depth of wall invasion was to the muscularis propria in three to the subserosa in six, and to the serosa in three. Lymph node metastasis was absent in seven, present in three, and not given in two. The disease was stage I in seven, stage II in two, and stage III in three. Nine patients were alive and free of disease at a follow-up of 5-10 years; three died of recurrence when more than 5 years had passed after operation.

\section{Discussion}

Perforation of gastric cancer is rare and is regarded as having poor surgical outcome. There is peritoneal contamination leading to sepsis and ileus, and there are nutritional and immunologic deficiencies, so that the patient is usually very ill. The gastric cancer is usually far advanced and is often accompanied by peritoneal dissemination, liver metastasis, and extensive lymph node involvement. Therefore, the control of sepsis, assessment of cancer extent, and decisions for operative intervention influence indications for surgical procedures. Gertsch et al. [3] stress that a significant proportion of patients can be saved and offered good palliation with emergency gastrectomy, although the decision on whether to submit patients to gastrectomy should be made on an individual basis.

In Western countries, most patients with perforation of gastric cancer were treated by simple closure or 
Table 1. Long-term survival after perforation of advanced gastric cancer

\begin{tabular}{|c|c|c|c|c|c|c|c|c|}
\hline Case & Age/sex & $\begin{array}{c}\text { Pre-opeartive } \\
\text { diagnosis }\end{array}$ & $\begin{array}{c}\text { Depth } \\
\text { of wall } \\
\text { invasion }\end{array}$ & $\begin{array}{l}\text { Lymph node } \\
\text { metastasis }\end{array}$ & $\begin{array}{l}\text { Stage of } \\
\text { disease }\end{array}$ & Operation & $\begin{array}{c}\text { Follow-up } \\
\text { period }\end{array}$ & Outcome \\
\hline 1 & $28 / F$ & Cancer* & $\mathrm{mp}$ & Absent & I & Distal/D2 & $10 \mathrm{y} 0 \mathrm{~m}$ & Alive \\
\hline 2 & $53 / \mathrm{M}$ & Cancer* & se & Present & III & Distal/D1 & $5 \mathrm{y} 0 \mathrm{~m}$ & Dead \\
\hline 3 & 49/M & Ulcer* & $\mathrm{mp}$ & Absent & I & Distal/D2 & $5 \mathrm{y} 0 \mathrm{~m}$ & Alive \\
\hline 4 & 79/M & ? & ss & Absent & I & Distal/D1 & $7 \mathrm{y} 0 \mathrm{~m}$ & Alive \\
\hline 5 & 75/M & Cancer* & ss & Present & II & Distal/D2 & $5 \mathrm{y} 0 \mathrm{~m}$ & Alive \\
\hline 6 & $54 / \mathrm{M}$ & Ulcer & ss & Absent & I & Distal/D2 & $5 \mathrm{y} 4 \mathrm{~m}$ & Alive \\
\hline 7 & $68 / F$ & Cancer & ss & Absent & I & Distal/D1 & $5 \mathrm{y} 0 \mathrm{~m}$ & Alive \\
\hline 8 & $54 / \mathrm{M}$ & Ulcer & ss & $?$ & I & Distal/? & $10 \mathrm{y} 0 \mathrm{~m}$ & Alive \\
\hline 9 & $57 / \mathrm{F}$ & Ulcer & Ss & Absent & II & Total/D1 & $6 y 2 m$ & Dead \\
\hline 10 & $?$ & Ulcer & $\mathrm{mp}$ & Absent & I & Distal/? & $9 \mathrm{y} 0 \mathrm{~m}$ & Alive \\
\hline 11 & $84 / \mathrm{M}$ & Ulcer & se & $?$ & III & Distal/D0 & $5 \mathrm{y} 10 \mathrm{~m}$ & Dead \\
\hline 12 & 49/M & Ulcer & se & Present & III & Total/D2 & $6 y 11 \mathrm{~m}$ & Alive \\
\hline
\end{tabular}

* Perforation associated with gastric endoscopy

?, data were not given; mp, muscularis propria; ss, subserosa, se, serosa; distal, distal gastrectomy; total, total gastrectomy; D0, no lymph node dissection; D1, Group 1 lymph node dissection; D2, Group 1 \& 2 lymph node dissection

omental patch $[1,2,14,15]$. Unsuccessful outcomes after these procedures were considered to be due to the poor condition of the patients and failure to controll sepsis. Gertsch et al. [3], in their recent report of surgical results in 34 patients with perforated gastric cancer in Hong Kong, found that a significant proportion of patients could be saved with emergency gastrectomy, and pTNM staging was the only factor that correlated with long-term survival. They carried out emergency gastrectomy in 30 patients $(88 \%)$, with a mortality rate of $16 \%$, and 6 patients were alive after a median time of 42 months.

Recently, we analyzed the surgical results of 155 Japanese patients with perforated gastric cancer reported during the previous 10 years [16]. There were 27 stage I tumors (19\%), 16 stage II tumors (12\%), 42 stage III tumors (30\%), and 55 stage IV tumors (39\%). Emergency gastrectomy was done in 128 patients $(83 \%)$ with a mortality rate of $7 \%$ and 5-year survival rate of $40 \%$. The survival rate was significantly influenced by the depth of wall invasion, presence or absence of lymph node metastasis, stage of the disease, and operative curability. The 5-year survival rate for stage I tumors was $93 \%$; for stage II tumors, $49 \%$; for stage III tumors, $34 \%$; and for stage IV tumors, $7 \%$. These 5 -year survival rates were comparable with those for patients who underwent elective surgery for non-perforated gastric cancer: $78 \%-96 \%$ for stage I patients, $46 \%-77 \%$ for stage II, $20 \%-51 \%$ for stage III, and $10 \%-20 \%$ for stage IV [17-21]. Therefore, it appears that tumor perforation and peritoneal soiling do not necessarily influence postoperative outcome. Since the stage of the disease is the only factor that correlates with survival $[3,16]$, long-term survival can be expected in curatively treated patients with stage I tumors. The series [16] indicates that emergency gastrectomy for perforated gastric cancer is mostly safe and useful, and that successful outcome can be expected in patients with stage I tumors.

Long-term survival after perforation of advanced gastric cancer was rare $[3,16]$. Our review of the Japanese and English literature demonstrated that 9 of 12 patients who were alive without recurrence more than 5 years after operation had stage I tumors [6-13]. Longterm survival after operation was characterized by stage I tumor without serosal invasion and lymph node metastasis. Although our patient had stage III tumor with both serosal invasion and lymph node metastasis, he has been free of recurrence for more than 83 months since the operation. Dissemination of tumor cells associated with perforation of gastric cancer has been a matter of concern. We consider the successful results in our patient may be attributable to the curative gastrectomy with lymph node dissection, aggressive intraoperative peritoneal irrigation, intensive postoperative chemotherapy, and the lack of tumor metastasis to the liver, peritoneum, and distant lymph nodes. Thus, precise macroscopic examination of the resected stomach during operation is important. Since early gastric cancers are sometimes accompanied by ulceration and perforation [22], intraoperative histologic examination is necessary when a definitive diagnosis of perforation of gastric cancer cannot be achieved by gross examination of the resected stomach. 


\section{References}

1. Cortese AF, Zahn D, Cornell GN. Perforation of gastric malignancy. J Surg Oncol 1972;4:190-206.

2. Stechenberg L, Bunch RH, Anderson MC. The surgical therapy for perforated gastric cancer. Am Surg 1981;47:208-10.

3. Gertsch P, Yip SKH, Chow LWC, Lauder IJ. Free perforation of gastric carcinoma: Results of surgical treatment. Arch Surg 1995;130:177-81.

4. Japanese Research Society for Gastric Cancer. The general rules for the gastric cancer study in surgery and pathology. Jpn J Surg 1981;11:127-45.

5. Adachi Y, Oshiro T, Okuyama T, Kamakura T, Mori M, Maehara $\mathrm{Y}$, et al. A simple classification of lymph node level in gastric carcinoma. Am J Surg 1995;382-5.

6. Ikeguchi M, Sakamoto H, Tamura H, Murakami S, Masaki T, Taniguchi $\mathrm{H}$, et al. Clinicopathological study of perforated gastric cancer (in Japanese with English abstract). J Jpn Soc Clin Surg 1986;47:343-7.

7. Hirayama R, Nibe Y, Hamada S, Iishi H, Mishima Y. The surgical therapy for perforated gastric cancer (in Japanese). Clin Surg 1987:42:325-9.

8. Osawa J, Higashide S, Tamagawa M, Yatagai T, Oguchi M, Shinoda M, et al. Clinical and pathohistological features of perforated gastric carcinomas: Study of eight cases (in Japanese). Jpn J Gastroenterol Surg 1987;20:1676-81.

9. Yara T, Harakuni M, Ajitomi S. Five-year survival after operation for Borrmann II type perforated gastric cancer (in Japanese). Okinawa Acta Med 1989;26:33-5.

10. Nakazaki $T$, Hashimoto $Y$, Ifuku M, Kubota F, Minami H, Takada T, et al. Clinical studies on the cases of perforated gastric cancer (in Japanese with English abstract). J Jpn Soc Clin Surg 1989;50:949-53.

11. Tomoda N, Uchino Y, Ikeda H, Shima H, Hara M, Ohashi M, et al. A study on operated cases of perforated gastric cancer (in Japanese with English abstract). J Jpn Soc Clin Surg 1993;54: 3071-6.
12. Takehana T, Imada T, Abe M, Suzuki M, Chen C, Takahashi M, et al. Clinical pathology and treatment of perforation in gastric cancer (in Japanese with English abstract). Jpn J Cancer Clin 1994;40:1647-52.

13. Adachi Y, Takahashi I, Okudaira Y, Kusaba I, Okita K, Nozoe T, et al. Seventy months survival after operation for perforated gastric carcinoma (in Japanese). Surg Ther 1996;75:613-6.

14. Aird I. Perforation of carcinoma of the stomach into the general peritoneal cavity. Br J Surg 1935;22:545-54.

15. McNealy RW, Hedin RF. Perforation in gastric carcinoma. Surg Gynecol Obstet 1938;67:818-23.

16. Adachi Y, Mori M, Maehara Y, Matsumata T, Okudaira Y, Sugimachi K. Surgical results of perforated gastric carcinoma: An analysis of 155 Japanese patients. Am J Gastroenterol 1997;92: 516-8.

17. Maruyama K, Okabayashi K, Kinoshita T. Progress in gastric cancer surgery in Japan and its limits of radicality. World J Surg 1987;11:418-25.

18. Pacelli F, Doglietto GB, Bellantone R, Alfieri S, Sgadari A, Crucitti F. Extensive versus limited limph node dissection for gastric cancer: A comparative study of 320 patients. Br J Surg 1993;80:1153-6.

19. Siewert JR, Böttcher K, Roder JD, Busch R, Hermanek P, Meyer HJ and the German Gastric Carcinoma Study Group. Prognostic relevance of systemic lymph node dissection in gastric carcinoma. Br J Surg 1993;80:1015-8.

20. Adachi Y, Mori M, Maehara Y, Sugimachi K. Dukes's classification: A valid prognostic indicator for gastric cancer. Gut 1994; 35:1368-71.

21. Söreide JA, van Heerden JA, Burgart LJ, Donohue JH, Sarr MG, Ilstrup DM. Surgical aspects of patients with adenocarcinoma of the stomach operated on for cure. Arch Surg 1996;131:4817.

22. Mukai M, Kondou Y, Ogoshi K, Noto T, Makuuchi H, Tajima T, et al. A case of perforated early gastric cancer and a review of 45 cases collected from the Japanese literature (in Japanese with English abstract). J Jpn Soc Clin Surg 1992;53: 1869-73. 